\title{
How Does Education Affect the Time Spending on Work and Leisure?
}

\author{
Yinghua International School, Tianjin, China
*363521476@qq.com
}

*Chen Ye

\begin{abstract}
I use the American Time Use Survey between 2003-2018 to study how education affects work and leisure time use. I find that higher education is associated with more time spent on work and less time on leisure. This is robust if we control the effect of income, gender, and age. In addition, we also find there has been a trend decline in work and an increase in leisure time over the sample period, which is mostly explained by the change in old people.
\end{abstract}

Keywords: Time Use, Education, Leisure, Labor Supply

\section{INTRODUCTION}

With the transformation of the society and the emerging new science and technology, people's time allocation between work and leisure may change. Furthermore, people may also differ in their time uses across income, age, and other demographics. Conventionally, economists think of work and leisure time spending as an optimal choice of labor supply given different income, this paper focuses on the impact of another demographic factor, the education. I try to examine to what extent education affects people's leisure/work time spending both through prices and preferences.

In theory, the relationship between the two could go different ways. A positive relationship between the education and work time could be due to two reasons. The first one is the substitution effect, meaning a higher opportunity cost of not working, i.e. higher income, encourages people to work more and take less leisure. The second one is the higher the education level, the more utility work can bring to people. On the other hand, the income effect will lead to a negative relationship between education and work time because higher labor income makes it less necessary to work as much as before to make the same level of income.

As to the relationship between education and leisure time, it could be positive because of the income effect, or could be negative if people with high education gains less utility compare to people with low education. In addition, the opportunity cost and cost of leisure activity itself of the high education group is higher than that of the low education group.

The ambiguity in the theoretical prediction warrants an empirical examination of the relationship. In order to do so, I use the data from the American Time Use Survey. This survey includes data from 2003 to 2018 and a total of 557231 households were surveyed. The survey recorded in great detail the time spending on finely defined categories of activities which could be collapsed into broad categories of work and leisure. We exclude people younger than 18 years older and older than 8 so to focus on the work-age population. Also, we restrict the education level to be at least a high school diploma and no higher than MIU.

We first divide the entire population into three education groups. We compute the average time spent on work and leisure of each group for each year. We find as the education level increases, time spent on leisure decreases but more time to work. When we control income, age and gender, this relationship still exists. We also examine the pattern of different kinds of leisure activities. We find that there is a positive relationship between education and leisure time in art, travel and participation in sports. However, for TV watching, soccom and relax, the negative relationship can still be seen.

Then, we undertake a set of regression analysis by jointly controlling for potential confounding factors such as income, gender and other effects. The estimation confirms the previous results based on group summary statistics. For leisure time, middle and high 
education groups on average spend 18.6 minutes and 37.3 minutes less than the low education group, respectively. For work time, middle and high education groups spend 5.3 and 13.5 minutes more than the low education group respectively.

\subsection{Related Literature}

This paper is related to three lines of literature. First, the literature that studies the trend and cross-sectional pattern of work and leisure time use. For instance, Aguiar and Hurst (2007) found that there was an increase in leisure time by both men and women during 1965-2004. Vandenbroucke (2009) found a decline in work hours in the first half of 20 century and attributed it to both technological progress and change in wage structure. Hall (2009) found the American work time per week declined in the first half of the 20th century. Francis et al. (2005) found Leisure time per capita and average lifetime leisure time have increased by only four or five hours per week over the past 100 years. Moreover, The number of hours worked by people in their prime years has barely changed, but the number of hours worked by young people aged 14 to 24 has fallen sharply. Greenwood and Vandenbroucke (2005) found that for 200 years, the average hours worked by each worker, whether in the marketplace or at home, have fallen. Bick et al. (2018) found that average hours worked by adults in low-income countries are much higher than in high-income countries. Also, within countries, the number of hours worked per person is also falling in most countries in terms of individual wages. Boppart and Krusell (2020) found that across countries, working hours have steadily declined at a rate of just under 0.5 percentage a year. The key to the reduction in working hours is the income effect, which outweighs the substitution effect. Aguiar and Hurst (2008) examined the change in time distribution in the United States between 1965 and 2003 and 2005. It found that the amount of time Americans allocated to leisure increased over that time, almost all of it before 1985 . They also find that leisure inequality has increased significantly since 1985, with less-educated men increasing their leisure allocation and more educated men reducing their leisure time. Aguiar and Hurst (2009) indicated that since 1965, leisure time for men and women has increased by about five and 3.5 hours a week, respectively. However, most of these increases occurred before 1985, and the trend towards women has been somewhat reversed over the past decade. Ramey (2007) found that men increased their leisure time by 14 hours, while women increased their leisure time by 3-5 hours. Furthermore, inequality in leisure trends among different educational groups is growing.

Second, the work that studies the interaction between leisure and labor supply. Mustre-del Rio (2015) reversed the prediction that employment will decline with wealth, a common feature of models without exante heterogeneity. Aguiar et al. (2017) found that young men spent less time on work than old men and women because they spent a lot of time playing computer games. Boerma and Karabarbounis (2020) found that over the past two decades, the average family's wages and expenses have increased and the average productivity of leisure time increases significantly.

Third, a broad range of work also utilizes the time use data to answer other economic questions. For instance, Peter and Lozano (2005) used the Census Bureau and the CPS data and found the percentage of employed men in the U.S. who regularly work more than 48 hours a week is higher today than it was 25 years ago. McGrattan et al. (2004) found the average number of hours worked per person per week in the U.S. market since World War II have been largely unchanged. Kopytov et al. (2020) used aggregate data from OECD countries, as well as disaggregated data from the United States and found that the decline in working hours is largely explained by the decline in the price of leisure time. Instead, they also found mixed evidence over the past few decades that higher wages have led to a decline in working hours. Owen (1971) empirically estimates the complementarity between leisure time and market recreation through the regression of leisure time demand on relative prices of leisure goods and services in America from 1900 to 1961.

This paper is novel compared to all of these existing works in following aspects. First, this paper particularly focuses on the relationship between the education and time use instead of describing the general trend or crosssectional pattern in time use behaviors. Second, the time horizon we focus on is the recent two decades between 2003 and 2018, for which the rapid development of the internet and smart cellphone has significantly changed people's entertaining and leisure activities. I found that during the sample period, as education level increases, the leisure time decreases but work time increases.

\section{AGGREGATE ANALYSIS}

\subsection{Leisure}

Figure 1 plots the average time of work and leisure by different education groups. As the educational level increases, leisure time decreases. Provided that people's optimal consumption depends on where they equalize the marginal cost and the marginal benefit consuming the leisure $(\mathrm{MC}=\mathrm{MB})$. Let us try to explain the pattern via the perspective of the marginal cost and the marginal benefit given the other is fixed, separately.

As to the marginal benefit, the benefit of leisure means the utility that leisure brings to people. Assuming the leisure activities that are consumed by different 
education groups are homogenous in quality and can be only differentiated by the time spent on it. Then given the fact that the high education group actually spends less time on leisure activity, it could be the case that the marginal utility from each additional unit of time on leisure by the high education group is lower. This might be driven by the preferences toward leisure versus work by different education groups. In particular, the higheducation group may find it less desirable to consume more leisure than the low education group.

However, it is important to note that this is based on the assumption that the leisure homogenous in every other dimension except for the time. More realistically, it is likely that more educated people care more about the certain kind of leisure activities that does not require the same amount of time. Or it is likely that the different education groups consume different kinds of leisure activities. For example, the high education group will spend time going to concerts or museums, etc, but the low education group may watch TV at home. This means that people with higher education can reap the same benefits with less leisure time as people with lower education because they have more high-quality leisure activities. For a more sophisticated analysis, we need to take into account the type and quality of leisure activities.

As to the marginal cost, the cost of leisure includes two parts, one is the opportunity cost, such as wages, the other one is the money expenditure on purchasing the leisure activities, such as the Netflix subscription fees, tickets and travel expenses.

For opportunity cost, people with high levels of education are more likely to earn high wages, so the opportunity cost of leisure for them is relatively higher than that of the low education group. Therefore, the high education group tends to spend less time on leisure activity. This is called the substitution effect - the activity with the higher opportunity cost should be consumed less. However, at the same time, there is another effect influencing people's decisions, which is called the income effect. It says that the people who can make more money within a certain amount of time are actually able to work less to obtain the same level of income and hence able to spend more time on leisure. Given that we observe the high-education group spends less time on leisure, we believe that the substitution effect exceeds the income effect. We can also directly attribute the differences in time use in leisure to the cost of leisure activities. People with a higher degree may typically have higher leisure costs per unit of time as they pursue higher-quality leisure activities, such as traveling abroad and going to the cinema. In contrast, people with a low degree may choose to watch TV at home in their free time, which is close to free. There is a big difference between the costs of these two kinds of leisure activities. Therefore, even if the opportunity cost of consuming leisure is the same between the two groups, the fact that the high-education group is faced with a higher unit cost of leisure will induce them to spend less time on it.

Despite the differences in time spent on leisure, all groups seem to experience the same trend of increase in leisure time over the past two decades [3][4]. We could also consider the causes of such a trend from the point of view of the marginal cost and the marginal benefit, separately, taking the other as given.

It is possible that the utility that each time unit of leisure brings to people has increased over time as the result of the emergence of the internet and mobile entertaining activities in the recent decade. These developments have enriched the variety of leisure activities such as social media platforms, i.e. Facebook and online streaming services Youtube. More importantly, these services have been freely accessible. Maybe people could only go to the park or cinema with friends in their free time in the past, but nowadays, they can do lots of interesting things they want freely on the internet. Therefore, the utility increases within a certain amount of time.

As to the marginal cost, nowadays, the cost of leisure becomes cheaper as many websites or applications provide free services for people to enjoy. For instance, they can read some e-books freely online instead of buying books from bookshops. In addition, there has been a gradual transformation in work arrangements that allows more people to conduct work more flexibly. As a result, the opportunity cost of consuming leisure measured by time has decreased. According to the substitution effect, if the opportunity cost decreases, people should spend more time on leisure.

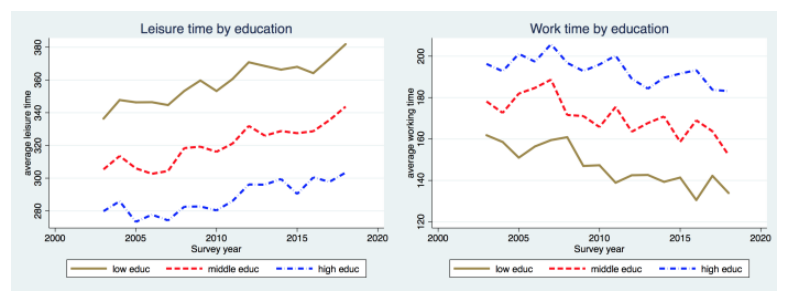

Notes.-Source: American Time Use Survey.

Figure 1 Average time spent on work and leisure by education group

\subsubsection{Different kinds of leisure}

In order to understand better if the leisure time use by education is particularly driven by certain types of leisure activities, we examine the same differences by focusing on the sub-category leisure activities. Figure 2 plots the average time of different kinds of leisure by different education groups. First of all, high-education group spends more time on some categories of the leisure activities, such as art, travel and participation in 
sports than the low-education group. This is the opposite pattern to the average leisure time spending. The reasons are possible that these activities are in nature more suited to the taste of the high- education group. Or these activities, especially, travel and art cost more money and high-education tends to have high income as well. At the same time, the general pattern of the negative correlation between education and leisure remains seen in the time on $\mathrm{TV}$ watching, social activities and relaxing activities. Importantly, TV watching accounts for over 40 to 60 percent of the total leisure time for both high and low education groups, respectively. Therefore, the average pattern is primarily driven by the time spent on this category.

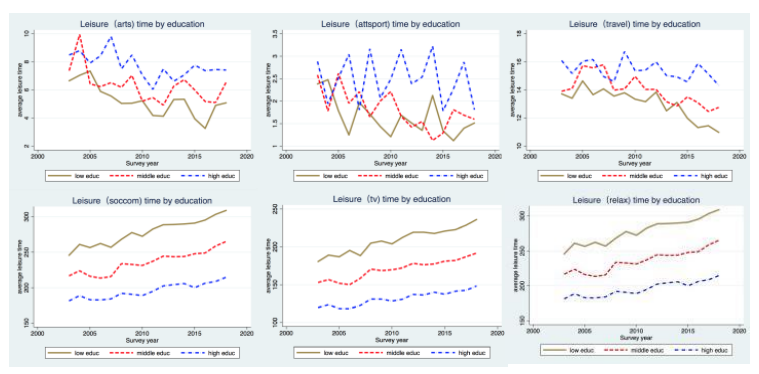

Notes.-Source: American Time Use Survey.

Figure 2 Average time spent on different kinds of leisure activities by education

\subsection{Work}

On the right of Figure 1 plots the average time of work by different education groups. It shows that as the educational level increases, working hours increase as well. We follow the similar analytical framework of marginal cost and the similar analytical framework of marginal cost and benefit to account for this difference as we do for the leisure time.

From the point of view of the marginal cost of work, people with high educational level tend to feel less disutility from work given they may enjoy work more than the low-education group. This may seem to be unrealistic at the first sight. However, if we consider the fact the people differ a lot in terms of the nature of the work they conduct depending on their education level, it is reasonable to argue that high-education groups can derive more sense of achievement, sense of creation and self-esteem by doing more creative and original work. This is in stark contrast with traditional blue- collar work that requires repetition and hard physical labor input.

From the point of view of the marginal benefit of the work, the most obvious form of the benefit comes as the monetary compensation for work, i.e. the wage and bonus. People with a higher level of education are more likely to earn a higher salary per unit of time, therefore, the marginal benefit from working a little more is higher than the low-education group. This logic is very similar to the interplay of substitution and income effect we have discussed for leisure, therefore, we do not repeat it here.

Exactly mirroring the trend for leisure [14], all education groups have spent less time on work overtime since the early 2000s [5][8][9][10][12][17]. To account for this, it seems that the marginal cost view may be more convincing. In particular, it could be driven by the income effect: over time, the average time that is necessary to sustain a comfortable level of life has been declining given the hourly wage has increased over the same period [6][7][11]. Therefore, people do not need to work as much as their optimal choices of time spending on work and leisure [13].

\section{SUB-GROUP ANALYSIS}

\subsection{By Income}

To explore how education level influence work and leisure time, we think that income may also be an influencing factor as there is likely a positive correlation between income and education levels. On the upper (lower) panel of Figure 3 plots the average time of leisure (work) within low, middle and high income group by education, separately.

These three pairs of graphs show the relationship between education and leisure/work respectively. We found that people with lower level of education have more leisure time and less work time than people with higher level of education, regardless of income group. So this may suggest that the substitution effect we discussed earlier can not be the only reason for the negative correlation between leisure time and education levels. According to the substitution effect, people with higher wage bear higher opportunity cost when they consume leisure, therefore they choose to consume less. But if we assume the income can approximate the wage, and we found here that within each income group, the correlation between education and leisure is still negative. Of course, it is the best if we can observe the wage of each individual, but the data we have does not have this information.

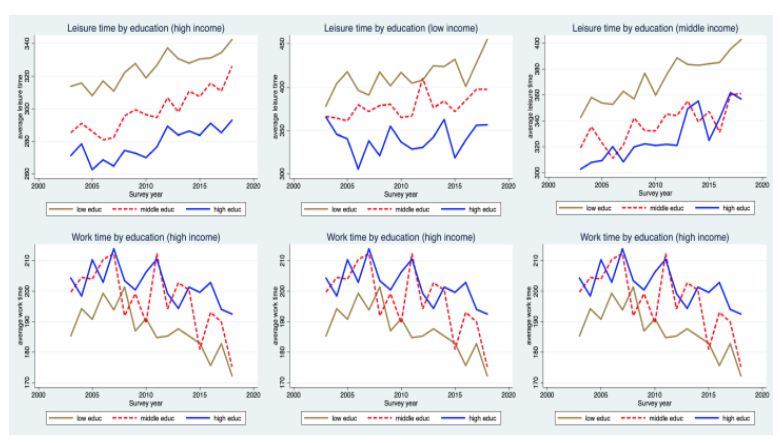

Notes.-Source: American Time Use Survey.

Figure 3 Average time spent on work and leisure by education and income 


\subsection{By Demographic}

To explore how education level influences work and leisure time, we think that age may also be an influencing factor because people of different ages may have different preferences between work and leisure. Figure 4 plots the age-specific average time of work and leisure by education.

The negative (positive) correlation between education and leisure (work) still exist within each age group. This suggests that age-specific preference cannot explain the relationship between education and work/ leisure.

However, compared to the earlier analysis, the upper trend of leisure time and the downward trend of work time we see for the entire sample over the period between 2003 and 2018 is no longer observable for young and middle-aged people. Only old people exhibit the same trend. Therefore, the aggregate trend we observed is driven by the change in behaviors of old people. There is a research showing that young people have spent more time on leisure over time and crowd out the labor supply [1]. Our evidence here does not seem to support this.

Another dimension of the demographics is the gender. Figure 5 plots the average time of work and leisure by males and females by education. Although gender is likely to be a confounder of education, it is still worth looking into if education affects the work and leisure choices of men and women differently. According to our graphs here, for both men and women, the pattern still exists. But at the same time, for each education level, we find that the men spend more time on work and less time on leisure than women do[16]. Another important pattern is that work time has decreased over time for both men and women[2][15]. It is widely known by researchers that women's work time and labor supply in general had increased from the 1960s till the early 2000s, because of the change in social norms, maternity leave policies, and the nature of work, etc. Our evidence here seems to confirm that the historical increase in work time of the women did stop during this period, even reversed.

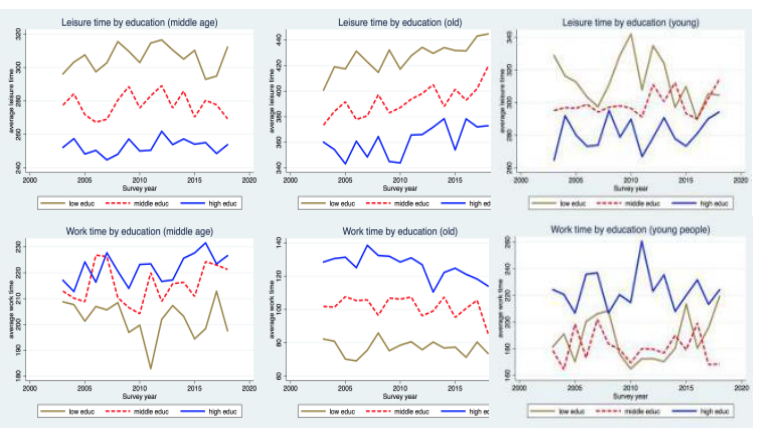

Notes.-Source: American Time Use Survey.

Figure 4 Average time spent on work and leisure by education and income

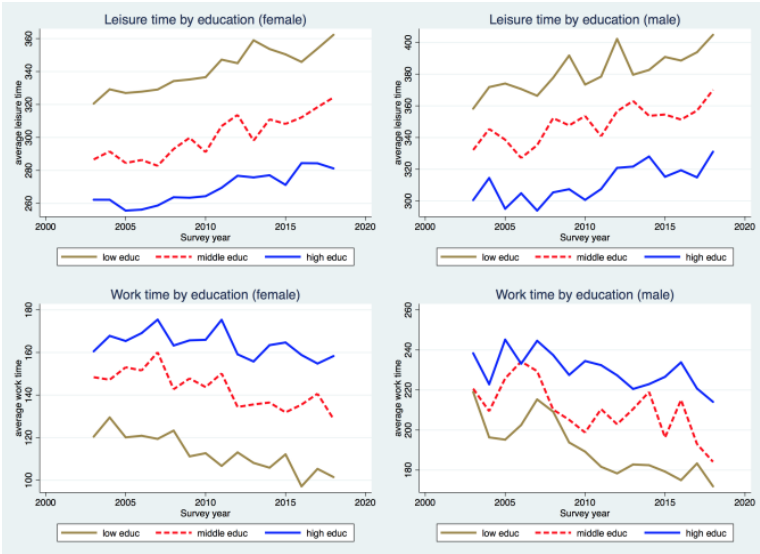

Notes.-Source: American Time Use Survey.

Figure 5 Average time spent on work and leisure by education and gender

\section{REGRESSION ANALYSIS}

In previous sections, we examined the relationship between education and time use separately conditional on income, gender and other factors. But one thing unclear is if these factors are correlated between themselves. Therefore, we need to control them all together so that our discovered relationship between education and time use is conditional on all factors together. Because of this, we undertake a linear regression analysis by controlling all factors that may be associated with time use.

Specifically, our regression is specified as the following.

$\tau_{i, t}=a+b_{1} E D_{i, t}+b_{2} I N C_{i . t}=b_{3} G E N_{i, t}+c_{t}+e_{i . t}(1)$

Notes: $\tau_{i, t}$ represents the work or leisure time of individual $i$ at time $t$. $a$ is the constant term in the whole equation that represents the average time spending of all people. $b_{1}, b_{2}, b_{3}$ are the coefficients of education (ED), income (NNC) and gender (GEN). They represents horr can change of education level, income and gender influence time use. $c$ represents the year-fixed effect. $e$ represents the influencing factors which are not explained by the variables we included.

Table 1 reports the regression results of the above specified model. We focus on the coefficients of education and income group. As the table shows, higher education is associated with lower leisure time and higher work time. In particular, compared to the low education group, middle-education and high-education group on average have 19 minutes and 37 minutes shorter in leisure time, as shown in the first column of the table. As to the work, shown in the last column of the table, the two groups have 5.3 and 13.5 minutes more than the low-education group. All the coefficients are statistically significant.

In general, the regression results have confirmed that as the education level increases, leisure time decrease and work time increases. For leisure and work, Rsquared are 0.12 and 0.10 respectively, this means that the explanatory power of data are strong. The sample size is 155778 . 
We also run the same regression using different type of leisure. It is shown in the 2 nd to the 7 th column of the table, that the leisure time spent on social, art and sport increase with education. In contrast, some leisure activities such as TV watching decreases with education. All coefficients are statistically significant. For social, TV, Relax, Art, Travel and Sport, R-squared are $0.01,0.11,0.17,0.00,0.02,0.10$ respectively.

Table 1 Baseline regression: time on work and leisure

\begin{tabular}{|c|c|c|c|c|c|c|c|c|}
\hline \multirow{3}{*}{ education group $=2$} & Leisu & Social & TV & Rel & Art & Travel & oort & Work \\
\hline & -18.577 & -.554 & $-22.84 !$ & -19.76 & & & $7533^{* *}$ & \\
\hline & [1.316] & & [1.041] & & & & {$[.343]$} & [1.631] \\
\hline education group $=3$ & $\begin{array}{c}-37.445^{* * *} \\
{[1.340]}\end{array}$ & $\begin{array}{c}-1.096^{*} \\
{[.618]}\end{array}$ & $\begin{array}{l}-51.966 * * * \\
{[1.060]}\end{array}$ & $\begin{array}{c}-45.236 * * * \\
{[1.191]}\end{array}$ & $\begin{array}{c}1.623^{* * *} \\
{[.252]}\end{array}$ & $\begin{array}{c}1.718^{* * *} \\
{[.233]}\end{array}$ & $\begin{array}{c}5.149^{* * *} \\
{[.350]}\end{array}$ & $\begin{array}{c}13.536 * * * \\
{[1.660]}\end{array}$ \\
\hline incom & $\begin{array}{c}-33.218^{* * *} \\
{[1.863]}\end{array}$ & $\begin{array}{c}-5.229^{* * *} \\
{[.859]}\end{array}$ & $\begin{array}{c}-23.019^{* * *} \\
{[1.473]}\end{array}$ & $\begin{array}{c}-31.635 * * * \\
{[1.655]}\end{array}$ & $\begin{array}{c}1.086^{* * *} \\
{[.350]}\end{array}$ & $\begin{array}{c}1.086^{* * *} \\
{[.324]}\end{array}$ & $\begin{array}{l}.915^{*} \\
{[.486]}\end{array}$ & $\begin{array}{c}58.720^{* * *} \\
{[2.308]}\end{array}$ \\
\hline income group=3 & $\begin{array}{l}-50.381^{* * *} \\
{[1.851]}\end{array}$ & $\begin{array}{l}-3.966^{* * *} \\
{[.853]}\end{array}$ & $\begin{array}{c}-45.463^{* * *} \\
{[1.464]}\end{array}$ & $\begin{array}{l}-58.928 * * * \\
{[1.645]}\end{array}$ & $\begin{array}{l}2.939 * * * \\
{[.348]}\end{array}$ & $\begin{array}{c}2.799 * * * \\
{[.322]}\end{array}$ & $\begin{array}{l}5.389^{* * * *} \\
{[.483]}\end{array}$ & $\begin{array}{l}86.946^{* * * *} \\
{[2.293]}\end{array}$ \\
\hline & & & 404 & & & & 02 & 10 \\
\hline Samp & 155788 & 155788 & 5788 & 578 & 15578 & 15578 & 155788 & 155788 \\
\hline
\end{tabular}

Notes: This table reports the coefficients from a regression of time in different kinds of leisure and work on the education and income levelof the individuals by controlling other demographic such as gender, regions, age, age square and time fixed effect. Education is grouped into three categories, low $\left(\right.$ educ $\left.{ }_{9} r=1\right)$, middle(educ $r=2)$ and high $\left(e d u c_{g} r=3\right)$.

\section{CONCLUSION}

The theoretical relationship between education level and work/leisure time spending could be either positive or negative. Empirically, this paper documents a negative relationship between work time and education and a positive between leisure time and education. This implies that the substitution effect likely outweighs the income effect. Another possible reason may have to do with preference heterogeneity across different education levels, i.e. a higher education increases people's preference for work and disutility from leisure. At the same time, specific to leisure, the negative relationship between the two could be also due to educationdependent preferences about different leisure activities. There are differences in the types of leisure activities consumed by different education groups. My paper also shows there has been a decade-long trend decline (increase) in work (leisure) time by an average household.

Admittedly, this paper mostly focuses on documenting the correlation between education and time use instead of identifying the causal effect between the two, since both variables could endogenously interact with each other. But I still establish a robust correlation between the two by controlling important confounding factors such as income and age. It highlights the importance of incorporating reasonable heterogeneity in time allocation across education groups. Future work could supplement my findings with better identification of the causal effect through exploiting exogenous variations in education.

\section{REFERENCES}

[1] Mark Aguiar, Mark Bils, Kerwin Kofi Charles, and Erik Hurst. Leisure luxuries and the labor supply of young men. Technical report, National Bureau of Economic Research, 2017.

[2] Mark Aguiar and Erik Hurst. Measuring trends in leisure: The allocation of time over five decades. The Quarterly Journal of Economics, 122(3):9691006, 2007.

[3] Mark Aguiar and Erik Hurst. The increase in leisure inequality. Technical report, National Bureau of Economic Research, 2008.

[4] Mark Aguiar and Erik Hurst. A summary of trends in american time allocation: 1965-2005. Social Indicators Research, 93(1):57-64, 2009.

[5] Alexander Bick, Nicola Fuchs-Schündeln, and David Lagakos. How do hours worked vary with income? cross-country evidence and implications. American Economic Review, 108(1):170-99, 2018.

[6] Job Boerma and Loukas Karabarbounis. Labor market trends and the changing value of time. Journal of Economic Dynamics and Control, page 103885, 2020.

[7] Timo Boppart and Per Krusell. Labor supply in the past, present, and future: a balancedgrowth perspective. Journal of Political Economy, 128(1):118-157, 2020.

[8] Neville Francis, Valerie A Ramey, et al. A century of work and leisure. In 2005 Meeting Papers, number 250. Society for Economic Dynamics, 2005.21

[9] Jeremy Greenwood and Guillaume Vandenbroucke. Hours worked: long-run trends. Technical report, National Bureau of Economic Research, 2005.

[10] Robert E Hall. Reconciling cyclical movements in the marginal value of time and the marginal product of labor. Journal of political Economy, 117(2):281-323, 2009.

[11] Alexandr Kopytov, Nikolai Roussanov, and Mathieu Taschereau-Dumouchel. Cheap thrills: the price of leisure and the global decline in work hours. Technical report, National Bureau of Economic Research, 2020.

[12] Ellen R McGrattan, Richard Rogerson, et al. Changes in hours worked, 1950-2000. Federal Reserve Bank of Minneapolis Quarterly Review, 28(1):14-33, 2004.

[13] Jose Mustre-del Rio. Wealth and labor supply heterogeneity. Review of Economic Dynamics, 18(3): 619-634, 2015. 
[14] John D Owen. The demand for leisure. Journal of Political Economy, 79(1):56-76, 1971.

[15] Kuhn Peter and Fernando Lozano. The expanding workweek? understanding trends in long work hours among us men, 1979-2004. NBER Working Paper, 11895, 2005.

[16] Valerie Ramey. How much has leisure really increased since 1965? University of California at San Diego Working Paper, 2007.

[17] Guillaume Vandenbroucke. Trends in hours: The us from 1900 to 1950. Journal of Economic Dynamics and Control, 33(1):237-249, 2009. 